\title{
CHARTIER, Roger: O que é um Autor? Revisão de uma genealogia
}

\author{
CHARTIER, Roger: What is an author? Revision of a \\ genealogy
}

\author{
VERONICA TORRES GURGEL \\ Universidade Federal do Rio de Janeiro
}

\begin{abstract}
Resumo: Esse artigo trata-se de uma resenha do livro O que é um autor? Revisão de uma genealogia, de Roger Chartier. Neste texto, publicado 30 anos após a conferência de Michel Foucault chamada $\mathrm{O}$ que é um autor?, Chartier retoma a discussão genealógica de Foucault, costurando-as e contrapondo-as, por vezes, às informações advindas de seu próprio percurso investigativo na área. Veremos como ambos apontam para a autoria como uma função, cujo desenvolvimento ocorre ao longo de um período histórico e frente a certas condições de possibilidade. Chartier traz para essa discussão uma complexidade ainda maior, indicando, por um lado, que o processos que dá início ao surgimento da função autor seria ainda mais antigo do que o proposto por Foucault. Por outro lado, frente às mudanças nas tecnologias de escrita, que permitem produção e leitura quase simultâneas, Chartier leva-nos questionar se a funçãoautor, tal como descrita 30 anos antes, não tenderia ao desvanecimento.
\end{abstract}

Palavras-chave: Função-autor. Escrita. Genealogia.

Abstract: This article is a review of Roger Chartier's book, What is an author? Revision of a genealogy. In this text, published 30 years after Michel Foucault's conference called "What is an author?", Chartier evokes Foucault's genealogy, aligning himself with him, but sometimes, opposing to him, according to the informations acquired by his own research in this field. We will see how both of them state that the author is a function, and tha it's development took place over a historical period of time, given certain conditions of possibilities. Chartier complexifies Foucault's discussion, by showing, on the one hand, that the author-function dates a period even earlier then what Foucault supposed it did. On the other hand, facing the changes in writing technologies, that allow that production and reading happen almost simultaneously, Chartier makes us wonder if the author function, as it was described 30 years earlier, wouldn't tend to disappear.

Keywords: Author-function. Writing. Genealogy. 
Em 1969, no Collège de France, Michel Foucault profere a conferência O que é um autor?. Trinta anos depois, em uma conferência chamada O que é um Autor? Revisão de uma genealogia, o historiador francês Roger Chartier recoloca esta questão, fazendo certos adendos que apontam para uma complexidade ainda maior que envolve esta pergunta. Em alguns pontos ele se distancia do discurso original, em especial ao sugerir uma revisão da extensão do período em que ocorre o surgimento da função autor, além da necessidade de incluir nessa genealogia a mudança dos suportes materiais dos textos. Por outro lado, ele abraça a importância e originalidade da investigação foucaultiana sobre essa questão. Em suas palavras, a

[...] genealogia da 'função autor' para os textos literários possui uma duração muito mais longa que aquela que Foucault nos sugeriu, e nesta genealogia de longa duração não podemos colocar em jogo unicamente a ordem do discurso, mas também a ordem dos livros [...]. (CHARTIER, 2012, p. 61).

Chartier (2012) retoma o que é a função autor para Foucault (2009), afirmando que ela é o resultado de operações complexas que conferem unidade e coerência a certos discursos, estabelecendo a maneira pelos quais eles circulam em dada sociedade, servindo como um "[...] princípio de economia frente à proliferação do sentido [...]" (FOUCAULT, 2009, p. 287). Como Chartier destaca, essa função se estabelece, principalmente, partir da atuação de dois processos.

O primeiro consiste em uma triagem dos textos, destacando, dentre todos, apenas aqueles aos quais essa função é atribuível. O segundo implica na construção da figura do autor e consiste na seleção dos traços pertinentes à sua caracterização. Portanto, o escritor é submetido a um processo de seleção, admissão e exclusão: nem tudo o que ele escreve é atribuído à função autor, assim como nem tudo o que ele faz é relevante para sua biografia, mas apenas aquilo que contribui para constituir uma unidade coerente e bem distinguível. Igualmente, o surgimento da função autor implica a seleção dos textos que compõe as obras, além do estabelecimento das suas chaves de leitura.

Portanto, tanto o autor quanto a obra surgem a partir de um mesmo tratamento que lhes é dispensado e que visa a criar certa homogeneidade e coesão. Logo, ele é uma

[...] função de classificação dos discursos, que permite as exclusões ou as inclusões em um corpus, atribuível a uma identidade única. Ela é, nesse sentido, fundadora da própria noção de obra e caracteriza certo modo de existência comum de alguns discursos que são atribuídos a um único lugar de expressão (CHARTIER, 2012, p. 29).

Uma das críticas feitas por Chartier (2012) ao longo da conferência O que é um autor? Revisão de uma genealogia diz respeito à cronologia proposta originalmente por Foucault. Assim, ele distingue e comenta os três tempos de estabelecimento da função autor que ele encontra no discurso foucaultiano ${ }^{1}$ :

\footnotetext{
${ }^{1}$ Embora Chartier analise esses tempos seguindo a ordem do discurso de Foucault, organizei-os aqui por ordem cronológica com vistas a facilitar seu entendimento.
} 
1. Séculos XVI - XVII

Em primeiro lugar, a função autor é objeto de uma apropriação penal, estando relacionada com a possibilidade de sanção dos indivíduos que produzem discursos transgressores. Para Foucault, a individualização das ideias está ligada à necessidade de legitimar certos discursos em detrimento de outros, por motivos políticos e religiosos.

O nome do autor é o que confere à obra autenticidade, distinção e um caráter de permanência. A função autor, portanto, indica de que maneira determinado texto deve ser recebido e qual estatuto deve adquirir. Nas palavras de Foucault:

\begin{abstract}
Os textos, os livros, os discursos começaram efetivamente a ter autores (outros que não personagens míticas ou figuras sacralizadas e sacralizantes) na medida em que o autor se tornou passível de ser punido, isto é, na medida em que os discursos se tornaram transgressores. (FOUCAULT, 2009, p. 274-275).
\end{abstract}

A noção de autoria foi sendo construída à medida que a obra passou a ser considerada como responsabilidade de um indivíduo específico. A importância da função autor pode ser atestada ao se verificar que a escrita de textos questionadores ou considerados inadequados frequentemente levava pessoas a serem julgadas como réus. Era preciso punir aqueles que escreviam os textos indesejados. Embora Foucault não date esse momento, pode-se deduzir que ele ocorre entre os séculos XVI e XVII (CHARTIER, 2012). Tal apropriação penal corresponde a uma ligação entre a função autor e a seleção de textos e autores passíveis de punição.

Como Chartier (1999) destaca, no começo da era moderna são numerosas as condenações de autores de textos considerados política ou religiosamente transgressivos:

\footnotetext{
Para identificar e condenar aqueles que eram seus responsáveis, era necessário designá-los como autores. As primeiras ocorrências sistemáticas e ordenadas alfabeticamente de nomes de autores encontram-se nos índices dos livros e autores proibidos, estabelecidos nos séc. XVI [...]. (CHARTIER, 1999, p. 34).
}

Ainda de acordo com Chartier (2012), há inúmeros textos que confirmam a existência dessa apropriação, o que a torna irrefutável. A título de exemplo, ele utiliza o Índex de Rojas Y Sandoval (índex de 1612, da Inquisição Espanhola). Nele havia três classes de condenação e em todas as três figura a função do nome do autor.

a) A primeira diz respeito à condenação de autores hereges ou suspeitos de heresia. São condenadas tanto as obras escritas quanto aquelas que podem vir a ser escritas futuramente.

b) A segunda se refere a títulos específicos. Como instrumento de identificação e supressão dessas obras, os livreiros e impressores devem expedir a cada 60 dias uma lista organizada em ordem alfabética de sobrenome dos autores dos livros que possuem em suas lojas.

c) A terceira classe condena todas as obras publicadas anonimamente.

Há, por fim, sobretudo no livro impresso, o aumento da presença do autor caracterizada por seu retrato, ou seja, dá-se a substituição de uma cena tradicional, a da dedicatória - na qual o autor era retratado ajoelhado 
entregando ao Príncipe a obra que escreveu, traduziu, compilou - pelo retrato do autor [...]. (CHARTIER, 2012, p. 56).

Embora muitos historiadores liguem a função autor ao surgimento do livro impresso, para Chartier isso não se verifica. Em primeiro lugar, porque o manuscrito convive com a publicação impressa, mas, mais fundamental ainda é a mutação do objeto livro, enquanto tal. Do século VIII até o século XIV ele é dominantemente caracterizado por miscelâneas. Isto é, e m um mesmo códice estavam presentes textos de autores, datas, origens, naturezas e gêneros variados. Sua organização em uma unidade não se baseava na função autor, mas, como sugere Chartier (2012), na função-leitor ou função-copista - que desejariam reunir esses textos por tais ou quais motivos. No entanto, nos séculos $X I V^{2}$ e XV “[...] começa a aparecer uma unidade entre o 'objeto' (livro), uma obra (compreendida num sentido singular ora como conjunto de textos produzidos por uma mesma mão, ora como um mesmo 'espírito') e o nome do autor [...]" (CHARTIER, 2012, p. 61).

Para Chartier, essa é a condição de possibilidade, uma espécie de base para que a função autor seja mobilizável e possa atuar como princípio de ordenação, identificação e atribuição das obras. Nesse momento começam a surgir retratos dos autores no interior dos manuscritos, que “[...] os representam, de modo um pouco ingênuo, no ato de escrever a obra que o leitor tem nas mãos [...]" (CHARTIER, 1999, p. 31-32).

2. Séculos XVII - XVIII

Foucault (2009) afirma que a função autor não é exercida de modo homogêneo, pois em cada sociedade, os variados discursos têm relações diferentes com a função autor. Para exemplificar essa característica, Foucault (2009) analisa uma mudança que teria ocorrido por volta dos séculos XVII e XVIII. Enquanto a veracidade dos textos científicos na Idade Média dependia do nome do seu autor ("Hipócrates disse"), hoje em dia esse tipo de discurso independe daquele que o fala (é a ciência quem diz, e não o cientista). Por sua vez, o inverso teria ocorrido com os textos "literários". Antes, anônimos, eles passam a ser cada vez mais vinculados ao nome dos seus autores. Dessa forma, Foucault afirma que a função autor é “característica do modo de existência, de circulação e de funcionamento de certos discursos no interior de uma sociedade" (FOUCAULT, 2009, p. 274).

Embora concorde que a função autor não atua de modo homogêneo, Chartier (2012) faz algumas ressalvas com relação às colocações de Foucault no que concerne este assunto. Segundo Chartier, a função autor não teria se apagado no discurso científico, na medida em que continua dependendo do “ [...] nome próprio daquele que tem autoridade o bastante para enunciar o que é verdadeiro em uma sociedade cuja hierarquia das ordens e do poder é ao mesmo tempo uma hierarquia das posições sociais e da credibilidade da palavra [...]" (CHARTIER, 2012, p. 52). Além disso, a própria distinção entre textos literários e científicos Ihe parece questionável.

3. Séculos XVIII - XIX

\footnotetext{
${ }^{2}$ Antes da publicação impressa, portanto, visto que a prensa de Gutenberg data de meados do século XV.
} 
Para Foucault (2009), o surgimento da função autor estaria diretamente relacionado com concepções burguesas de propriedade e indivíduo, na medida em que a questão do direito de propriedade nas obras surgiria nas relações no fim do século XVIII e início XIX. De acordo com Chartier (2012), no entanto, essa afirmação está equivocada, pois o autor-proprietário teria surgido ainda no começo do século XVIII. Segundo ele, a definição da propriedade literária não surge como um caso particular de propriedade burguesa com vistas a defender os direitos do autor. Ao contrário, ela surge para proteger o direito do livreiro editor.

Para demonstrar essa sua afirmação ele retoma a história dos direitos autorais na Inglaterra. Por volta do século XVI a Stationers' Company, comunidade dos livreiros e impressores, é orientada por uma dupla regulamentação:

a) Somente seus membros podem registrar textos - o que impede que autores não Iondrinos se tornem editores.

b) Reivindicam a perpetuidade dos direitos adquiridos junto aos autores - podendo, inclusive, deixá-los como herança.

Somente os manuscritos depositados na Stationers' Company possuem o right in copies, isto é, tem suas cópias regulamentadas. Todavia, em 1709 esse monopólio é quebrado: passase a permitir que os autores registrem suas obras e sejam seus próprios editores. Além disso, os direitos à obra perduram por 14 anos (e mais 14 suplementares se o autor ainda estiver vivo).

Para Chartier (2012), é nesse momento que se inventa o autor-proprietário da obra, justificado em duas bases. A primeira seria uma teoria do direito natural. De acordo com ela, o homem é proprietário do seu corpo; portanto, ele também é proprietário dos frutos do seu trabalho; como textos literários são produtos de um trabalho, logo aquele que o realizou é seu proprietário legítimo. A segunda é de ordem estética e se apoia na originalidade, na singularidade do estilo da obra. O critério da originalidade parte de uma equivalência implícita entre as composições literárias (textos estéticos, filosóficos ou ficcionais) e as invenções técnicas (máquinas, procedimentos ou técnicas), para as quais havia a patent, que garantia seus direitos de exploração por um período de 14 anos.

Chartier (2012) busca demonstrar que, em oposição a essas decisões, os livreiros da Stationers' Company pretendem afirmar que obras literárias não são equivalentes a invenções técnicas. Isso porque o autor de um texto deveria ser proprietário perpétuo. Dessa forma, uma vez que o texto fosse cedido - ou vendido - a outra pessoa, essa perpetualidade seria transmitida junto com o escrito.

Surge, desse modo, uma tensão: por um lado, equipara-se o copyright a uma patente. Por outro, os editores livreiros buscam diferenciar a obra literária das invenções técnicas, pois não dependeriam de sua materialidade. Com isso começa a surgir uma diferenciação entre a "[...] irredutibilidade singular de um ato criador, de uma genialidade sem igual e, de outro, todas as formas particulares que podem ser dadas a esta obra [...]" (CHARTIER, 2012, p. 46), isto é, seus diferentes veículos. Podemos, claramente, perceber como essas duas visões permanecem presentes em nosso senso comum até os dias de hoje - não é a toa que falamos que um texto tem a assinatura do seu escritor para nos referirmos a esse estilo pessoal. 
Como historiador com grande interesse nas mudanças materiais pelas quais os livros passaram, Chartier (2012) enfatiza a desmaterialização das obras, que faz com elas sejam pensadas apenas em relação às categorias estéticas ou intelectuais em detrimento dos suportes que lhes são dados. Como ele demonstra, delineia-se, assim, uma discriminação entre o livro enquanto objeto material, e o texto abstrato.

Apesar de todas essas transformações, Chartier (2012, p. 47) atenta para que “[...] não se pode pensar que a propriedade sobre as obras nasce somente com essa dupla reflexão filosófica e estética do século XVIII [...]". Como ele demonstra, mesmo antes desse período já havia movimentos de constituição do autor como proprietário, havendo casos de autores que vendiam suas obras ${ }^{3}$.

A distinção entre a obra e seus diferentes suportes materiais leva a outra diferenciação. Segundo Chartier (2012), na Inglaterra do século XVIII os conceitos de property e propriety ${ }^{4}$ começam a se relacionar e, assim, a definir as duas faces da propriedade literária de hoje: os direitos morais e os direitos econômicos. A property está relacionada com o direito econômico, que permite tornar um escrito um bem rentável. Propriety, por sua vez, diz respeito aos direitos morais do autor e tem como objetivo preservar sua reputação, opinião e honra. Ela diz respeito, assim, a mudanças que corrompem o conteúdo do texto, que omitem trechos ou lhe acrescentam outros.

Em suma, com base em Chartier (2012), podemos resumir brevemente o esboço da cronologia da função autor da seguinte forma: séculos XIV e XV começa a surgir a unidade entre livro, obra e nome do autor; entre os séculos XVI e XVII inicia-se a apropriação penal do nome do autor; por fim, no início do Século XVIII surge o autor-proprietário, a exemplo da quebra do monopólio da Stationers' Company. Todavia, é preciso enfatizar que essas demarcações cronológicas não implicam datas rígidas, em que essas mudanças teriam ocorrido subitamente, mas são marcos para a história da função autor e das lentas mudanças que foram possibilitando sua emergência. Assim, Chartier chega a uma de suas teses, afirmando que

[...] uma nova forma do livro produz novos autores, ou seja, que a construção do autor é uma função não apenas do discurso, mas também de uma materialidade, materialidade e discurso que na minha perspectiva de análise são indissociáveis. (CHARTIER, 2012 p. 62-63).

Essa afirmação é de suma importância, pois vemos surgirem diversos suportes materiais para o escrito, que implicam em uma maior maleabilidade dos textos. O leitor pode, inclusive, intervir em seu conteúdo quase que no mesmo momento de sua escrita. Assim, haveria uma tendência ao desvanecimento da função autor, tal como descrita por Foucault (CHARTIER, 1999). Essas tecnologias de escrita permitem colocar novas questões para pensar o autor, na medida em que fazem com que escrita, edição e leitura tornam-se tarefas cada vez mais

\footnotetext{
${ }^{3}$ Tal distinção pode ser verificada com clareza no caso peças de teatro de Ben Johnson, que vendeu suas peças aos livreiros-impressores mesmo após tê-las vendido às trupes que as interpretavam (CHARTIER, 2012).

${ }^{4} \mathrm{Em}$ português, ambas as palavras seriam traduzidas como propriedade, não havendo a mesma diferenciação que no inglês.
} 
inseparáveis. Tema que se faz presente nos dias de hoje nos debates acerca dos direitos autorais.

\section{Referências}

CHARTIER, R. Os Desafios da Escrita. São Paulo: Ed. UNESP, 1999.

CHARTIER, R. O que é um Autor? Revisão de uma genealogia. São Carlos: EdUfSCar, 2012.

FOUCAULT, M. Ditos e Escritos. Estética: literatura e pintura, música e cinema. Rio de Janeiro: Forense Universitária, 2009. V. 3.

Recebido em 02 de maio de 2014

Aprovado para publicação em 19 de outubro de 2015

\section{Veronica Torres Gurgel}

Universidade Federal do Rio de Janeiro - UFRJ, Rio de Janeiro, Brasil. E-mail: vgurgel@gmail.com 